\title{
Examining the Psychosis Continuum
}

\author{
Pamela DeRosse • Katherine H. Karlsgodt
}

Published online: 15 March 2015

(C) Springer International Publishing AG 2015

\begin{abstract}
The notion that psychosis may exist on a continuum with normal experience has been proposed in multiple forms throughout the history of psychiatry. However, in recent years, there has been an exponential increase in efforts aimed at elucidating what has been termed the "psychosis continuum." The present review seeks to summarize some of the more basic characteristics of this continuum and to present some of the recent findings that provide support for its validity. While there is still considerable work to be done, the emerging data holds considerable promise for advancing our understanding of both risk and resilience to psychiatric disorders characterized by psychosis.
\end{abstract}

Keywords Subclinical psychosis · Schizotypy $\cdot$ Psychosis continuum

\section{Introduction}

The idea that psychosis may exist on a continuum with normal experience has been proposed in multiple forms throughout the history of psychiatry [1]. Over the last 20 years, however,

This article is part of the Topical Collection on Psychosis

P. DeRosse $\cdot$ K. H. Karlsgodt

Center for Psychiatric Neuroscience, The Feinstein Institute for

Medical Research, Manhasset, NY, USA

P. DeRosse $(\bowtie) \cdot$ K. H. Karlsgodt

Division of Psychiatry Research, The Zucker Hillside Hospital, Division of the North Shore-Long Island Jewish Health System, 75-59 263rd Street, Glen Oaks, NY 11004, USA

e-mail: pderosse@lij.edu

K. H. Karlsgodt

Department of Psychiatry, Hofstra North Shore-LIJ School of Medicine, Hempstead, NY, USA there has been an exponential increase in efforts aimed at elucidating what has been termed the "psychosis continuum" [2]. While the origin of this increased interest is complex and beyond the scope of the present review, the outcome has been to induce a lively [see 3] and accompanying commentary] and, in some cases, divisive [see 4] and accompanying commentary] debate about the existence and form of this continuum. Much of the criticism directed at the study of the psychosis continuum has centered around concerns that such theories may serve to blur the existing diagnostic categories. However, as aptly pointed out by Kaymaz and van Os [5], the idea that psychotic experiences occur in the general population can only undermine diagnostic categories if "diagnoses like 'schizophrenia' represent valid nosological entities," an issue that is rigorously debated in the field (i.e., 6]. Perhaps, a more valid point of contention regarding the utility of studying the psychosis continuum is whether it provides a better opportunity for elucidating the pathophysiology of psychosis than the current approach of biologically dissecting heterogeneous categories [4]. We would argue, however, that both approaches are needed and may serve complementary roles in untangling the complex architecture of psychotic disorders. Specifically, while the study of heterogeneous patient samples offers opportunities to examine the pathophysiology underlying risk for psychotic disorders, the examination of otherwise healthy individuals who exhibit sub-syndromal psychotic symptoms but who do not meet criteria for a psychiatric disorder offers opportunities to examine the pathophysiology of resilience to these disorders.

\section{Defining the Psychosis Continuum}

The psychosis continuum encompasses a full range of psychotic symptom expressions from sub-syndromal or "subclinical" manifestations to the clinically significant 
psychotic symptoms typically observed in individuals diagnosed with a psychiatric illness. Subclinical psychotic symptoms such as ideational thinking or altered perceptual experiences are often distinguishable from clinically significant psychotic symptoms such as delusions and hallucinations, based on features of the symptoms themselves such as severity, frequency, and conviction [7]. However, in some cases, the features of subclinical psychotic symptoms may, at least in some ways, be indistinguishable from the features of psychotic symptoms observed in patients with psychiatric illness. For example, Johns and colleagues [8•] recently reviewed the available data on auditory verbal hallucinations (AVH) in otherwise healthy individuals and compared them to data on patients with psychotic illness. Although they noted differences in the emotional valence of these experiences as well as differences in the appraisals and behavioral responses to these experiences, they noted very few differences in the basic qualities (i.e., severity, frequency, conviction) of the AVH between the non-clinical and clinical samples.

Modern approaches to the study of the psychosis continuum derive from two primary models that differ most notably in their predictions about the frequency of subclinical symptoms across the full population. The quasi-dimensional model derives primarily from the work of Meehl $[9,10]$ who suggested that a "dominant autosomal schizogene" produced an aberration in synaptic signal selectivity that produced a defect in neurointegrative processes that he called "schizotaxia". Meehl [10] asserted that under certain circumstances, schizotaxia gave rise to schizotypy, "a personality showing ambivalence, aversive drift, dereism, autism, and cognitive slippage" and that schizotypy was a necessary, but not sufficient, precursor for the emergence of schizophrenia. In this way, the quasi-dimensional model posits a continuum of psychosis ranging from aberrant personality characteristics (i.e., magical thinking) to the clinically significant psychotic symptoms associated with psychotic disorders (i.e., delusions). Notably, however, Meehl believed that only $\sim 10 \%$ of the population carried the "schizogene," and thus, only a small percentage of the population could be represented across the psychosis continuum. While it is now clear that psychotic disorders are genetically complex, likely involving thousands of genetic variants rather than a single fully penetrant risk allele [11], Meehl's quasi-dimensional model is at least partly supported by data derived from studies of schizotypal personality [for an excellent review of these data, see 12]. In contrast, the fully dimensional model, which derives primarily from the work of Claridge [13, 14], assumes that psychotic symptoms exists along a continuum across the full population. In Claridge's view, symptoms of psychosis may be adaptive or detrimental depending on simultaneous variation along some other dimensional characteristic (i.e., intelligence). For example, he noted that highly creative individuals displayed many symptoms characteristic of schizophrenia (i.e., withdrawal, emotional instability, eccentricity, etc.). However, although a very creative healthy individual may be predisposed to schizophrenia, they do "not become clinically psychotic because high general intelligence confers some immunity in the form of adequate intellectual and personality reserves" [14].

It is not yet clear which model, quasi- or fully dimensional, best fits the available data. In practice, however, much of the recent work seeking to elucidate the psychosis continuum ascribes to one model or the other based solely on the operational definitions of subclinical psychotic symptoms. For example, while the Schizotypal Personality Questionnaire (SPQ) [15] is generally viewed as a measure based on the quasidimensional model, the Community Assessment of Psychic Experience (CAPE) [16] is generally viewed as a measure based on the fully dimensional model. However, little is known about the extent to which measurements derived from these scales differ from one another. Indeed throughout much of the literature, symptoms assessed in otherwise healthy individuals using these (and a multitude of other) scales are typically collectively referred interchangeably as schizotypy and subclinical psychotic symptoms.

\section{Epidemiology}

Subclinical psychotic symptoms are common in the general population. They have an estimated prevalence of $7.2 \%$, with prevalence of specific symptoms ranging from $4.8 \%$ for delusions of control to $8.4 \%$ for delusions of reference and persecution [17], and an annual incidence of $2.5 \%$ [18••]. Although these rates are nearly double those of psychotic disorders [19], data suggest a functional relationship between the rates of subclinical symptoms and psychotic disorders in a given population. For example, in a random population study of over 7000 individuals, van Os and colleagues [20] found that as the rate of psychotic disorders increased as a function of greater levels of urbanicity in five distinct regions ranging from very rural to very urban, the level of subclinical symptoms in the healthy populations within the same regions also increased in a dose-dependent fashion. These data suggest that subclinical symptoms, even at a gross population level, bear a linear relationship to clinically significant psychotic symptoms and may suggest that they represent the behavioral expression of an underlying predisposition for psychotic disorders.

Notably, epidemiological studies also suggest that the prevalence of subclinical psychotic symptoms during late childhood and adolescence is exponentially higher than in adult populations with estimates generally between 40 and $66 \%$ $[21,22]$. Moreover, evidence suggests that subclinical psychotic symptoms are age related, peaking in adolescence and decreasing thereafter [23-25]. The extraordinarily high prevalence of subclinical psychotic symptoms during late 
childhood and adolescence has led to the suggestion that these symptoms may represent the behavioral expression of normal neurodevelopmental processes [26]. However, prospective longitudinal studies have demonstrated that high levels of subclinical psychotic symptoms often predict, albeit weakly, the onset of later psychiatric illness. For example, Chapman and colleagues [27] initially demonstrated that individuals who were rated high on scales of magical ideation and perceptual aberration had high rates of psychotic outcomes 10 years later and Poulton et al. [28] found that $25 \%$ of children with psychotic experiences at age 11 developed schizophreniform disorder over a 16-year follow-up period. These results have been further replicated in several distinct cohorts [29-32] and collectively suggest some continuity between subclinical and clinically significant psychotic symptoms.

\section{Evidence for Similarity Between Subclinical and Clinically Significant Psychosis}

The evidence supporting the continuity from subclinical to clinically significant psychotic symptoms derives from multiple sources including (1) data demonstrating similarities in the clinical profiles of patients with psychotic disorders and healthy individuals who report subclinical psychotic symptoms, (2) substantial overlap in demographic and experiential risk factors for psychotic disorders and subclinical psychotic symptoms, and (3) evidence derived from family-based and molecular genetic studies. Moreover, data from brain imaging studies has recently begun to emerge suggesting that there may also be overlap in the structural and functional correlates of psychotic symptoms across the psychosis continuum. The following sections represent a selective review of some of the more recent findings in these areas.

\section{Clinical Profiles}

A critical issue that has received scant attention in the literature is whether or not the psychotic symptoms assessed in healthy samples bear a resemblance to the psychotic symptoms assessed in patient samples. Indeed, we are not aware of a single study whose primary aim was to directly compare patient and healthy samples on the same measure of psychotic symptoms. Data derived from our ongoing studies, however, provide at least some evidence for overlap in the symptom dimensions measured in these two samples (unpublished data). Figure 1 shows preliminary data from both healthy individuals and stable outpatients with schizophrenia or schizoaffective disorder assessed using the CAPE. We have previously demonstrated the validity of self-reported symptoms as measured by the CAPE subscales in the patient sample by comparing them to scores obtained on standard clinician-administered rating scales [33]. As the figure illustrates, there is considerable overlap in the distribution of symptom scores across these samples. Notably, permutation testing on the skewness of the patient vs. healthy distributions for both positive and negative symptoms reveals that the shapes of the distributions do not significantly differ, despite the obvious difference in mean scores.

Considerably more attention has been directed to examining similarities in comorbid symptoms in patient and healthy samples. Specifically, a large body of work has sought to examine whether the high rate of comorbid depressive symptoms observed in patients with psychotic disorders is evidenced at the subclinical end of the psychosis continuum. These efforts have revealed that in both adults [34] and adolescents [35-37], subclinical psychotic and depressive symptoms are significantly interrelated, although they may not be predictive of one another longitudinally [37]. Recent data from Klaassen and colleagues [38] provide direct support for the overlap between psychotic and depressive symptoms across the continuum. Specifically, they demonstrated in a large sample of patients, healthy siblings, and healthy controls that the number and duration of depressive symptoms were significantly associated with the severity of psychotic symptoms in all three groups.

The overlap in clinical symptom profiles between psychotic disorders and subclinical psychotic symptoms also extends to premorbid personality characteristics. Specifically, similar patterns of personality traits have been observed between clinically significant psychosis phenotypes, including schizophrenia and schizotypal personality disorder [39-41] and dimensions of schizotypy in otherwise healthy individuals [42-45]. Indeed, the concept of schizotypy [9, 46, 47] has considered psychosis proneness as a personality framework itself [42, 48] and studies using a range of personality measures have identified a consistent pattern of personality traits that are shared between patients exhibiting clinically significant psychotic symptoms and otherwise healthy individuals who exhibit high levels of schizotypal or subclinical symptoms. For example, studies using Cloninger's temperament and character inventory (TCI) [49] have found that both groups score high on harm avoidance and self-transcendence as well as low on reward dependence, novelty seeking, self-directedness, and cooperativeness [43, 50-52].

Although the overlap in personality profiles noted above may provide some insight into risk for psychotic disorders, we have recently identified some differences between the personality profiles of patients with psychotic disorders and otherwise healthy individuals who exhibit high levels of schizotypy. Specifically, while previous work found that patients with schizophrenia were characterized by low persistence and low cooperativeness, in a sample of 415 healthy individuals, we found that high persistence was linked with high levels of positive subclinical symptoms and high 
Fig. 1 Distribution of scores on the Community Assessment of Psychic Experience (CAPE) in healthy volunteers and patients with schizophrenia or schizoaffective disorder. Patients were stable (no hospitalizations in previous 6 months) at the time of the assessment. a Distribution of positive symptoms. b Distribution of negative symptoms

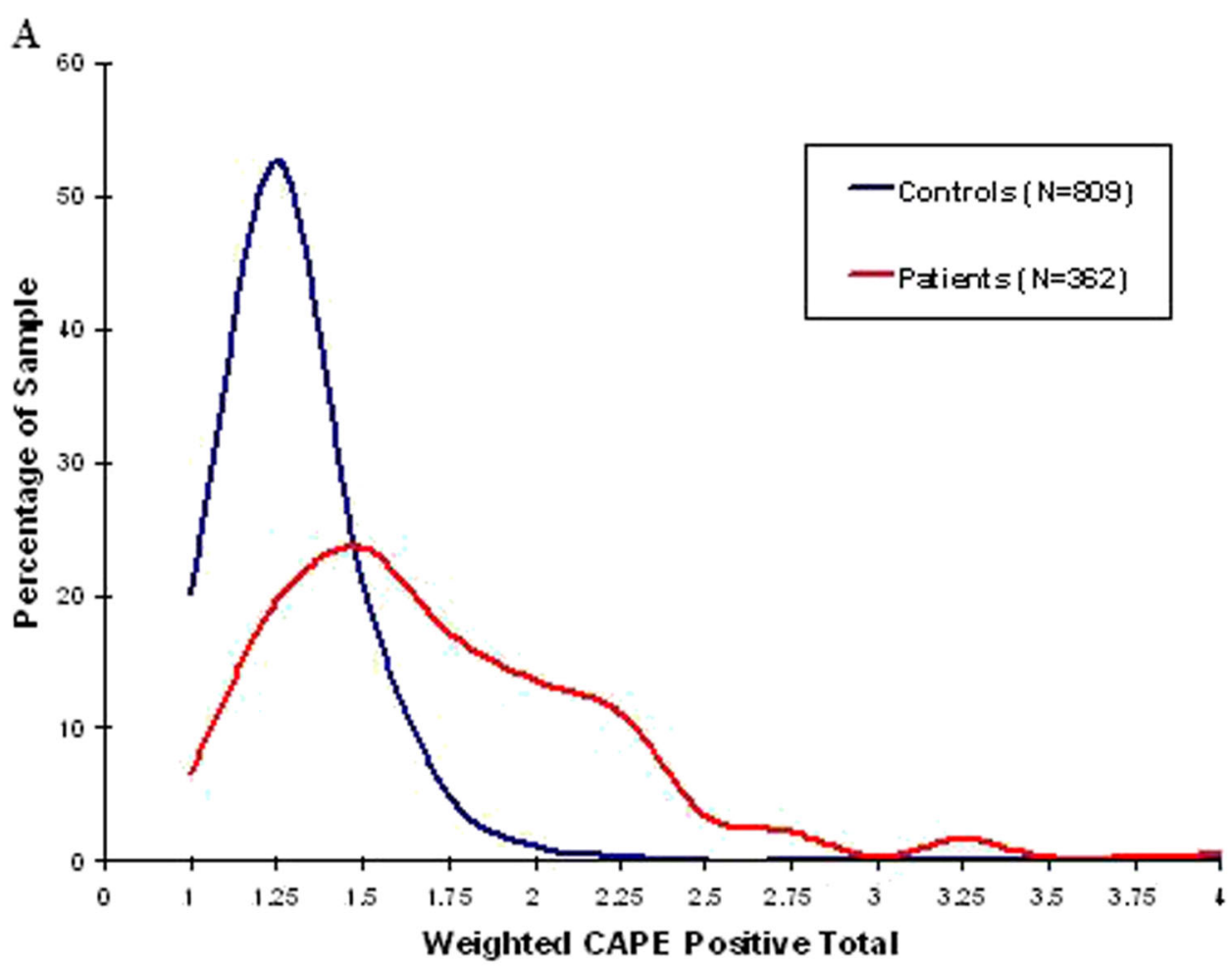

B

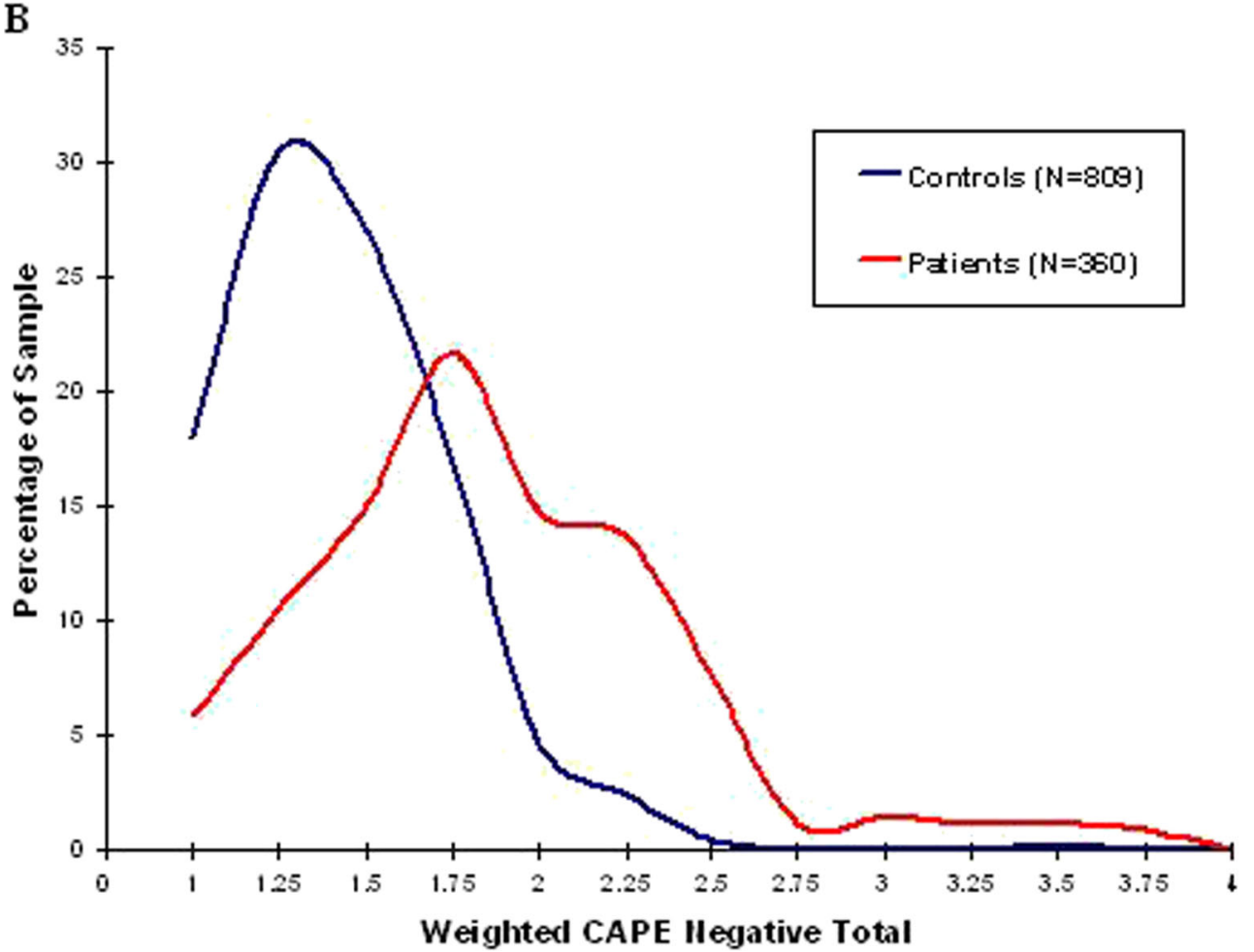

cooperativeness was linked with high levels of negative subclinical symptoms [52]. These findings may suggest some potential resilience factors that separate those on the subclinical end of the psychosis continuum from patients with psychotic disorders. Specifically, it is possible that higher persistence confers a greater ability to overcome the adversity associated with positive symptoms and higher cooperativeness confers a greater capacity to resist tendencies toward social withdrawal and a greater ability to accept social support from others. Thus, these personality traits may act to mitigate 
the risk of transition from subclinical to clinically significant psychosis. Although these results have not yet been replicated, these preliminary findings suggest that the comparison of patients with clinically significant psychotic symptoms to otherwise healthy individuals with high levels of subclinical psychotic symptoms may provide some insight into the mechanisms of resilience to psychotic disorders.

\section{Neurocognition}

These observed similarities in clinical profiles between subclinical psychosis and clinically significant psychotic disorders have prompted some researchers to hypothesize that neurocognitive deficits might also show a dose-response relationship across the psychosis continuum. Deficits across a range of cognitive skills have increasingly been recognized as a core feature of psychotic illness, with cognitive deficits manifesting in schizophrenia, schizotypal personality disorder, and schizophrenia patients' unaffected first-degree relatives [53-55]. However, despite large-scale longitudinal birth cohort data implicating deficits in general cognitive function (g) at ages 8,11 , and 15 in the manifestation of later subclinical psychotic symptoms in middle age [56], cross-sectional studies investigating the role of subclinical psychosis in neurocognitive performance have produced inconsistent results. While some studies have linked subclinical psychosis to deficits in cognitive function including visual memory and visuoconstructive performance [57], verbal fluency [58-60], working memory [61], selective and sustained attention [60, 62-65], cognitive set shifting [66], and capacity for abstract reasoning [66], other studies have found no significant links between subclinical psychosis and performance deficits in these cognitive areas [67-73]. Many of these studies, however, have been limited by small sample sizes, inclusion of only college students, inconsistent definitions of subclinical psychosis, and a lack of consistency in the cognitive domains examined.

More recently, our group [74] reported the results of data derived from a large $(n=303)$ and demographically diverse non-clinical sample in which we examined the relationship between sub-syndromal positive and negative psychotic symptoms and performance on the MATRICS Consensus Cognitive Battery (MCCB), a test battery designed specifically to assess cognitive domains that are reliably impaired in psychotic disorders [75]. We found that high levels of positive subclinical psychotic symptoms were associated with significantly better performance on measures of working memory, verbal learning, and visual learning as measured by the MCCB. Moreover, those who scored high on negative subclinical psychotic symptoms evidenced significantly better performance on a measure of general cognitive ability (WRAT-3). These results are in line with the idea that higher cognitive capacities may act as a resilience factor against clinically significant psychosis [14, 76, 77]. Specifically, data suggests that the risk of transitioning from subclinical to clinically significant psychotic symptoms is significantly associated with impaired neurocognitive function [78]. Conversely, it is possible that better cognitive function acts as a protective mechanism to prevent such a transition. Although these findings will require replication in larger samples, these preliminary findings also highlight the potential utility of examining the psychosis continuum for the identification of potential resiliency factors.

\section{Risk Factors}

A recent review and meta-analysis of the literature on subclinical psychosis in healthy populations spanning over two decades [18••] found that nearly all of the demographic and experiential risk factors for psychotic disorders predicted greater risk of subclinical psychotic symptoms in otherwise healthy individuals. Due to limited space, however, we will limit the present review to a single risk factor that has recently received the lions' share of attention in the literature.

\section{Childhood Trauma}

Several studies have demonstrated an association between childhood maltreatment and psychotic disorders, and a recent review and meta-analysis of these studies [79] found that childhood adversity is substantially associated with an increased risk for psychosis with a population attributable risk of $\sim 33 \%$. A substantial body of literature supports the extension of this relationship to subclinical psychotic symptoms. For example, Kelleher and colleagues [80] recently demonstrated a dose-response relationship between childhood trauma and psychotic experiences in a large prospective cohort of adolescents followed over a 12-month period. Specifically, they found that the odds of psychotic experiences increased in line with increasing levels of bullying and physical assault. These data are consistent with findings suggesting that patients with psychotic disorders often have a more severe history of childhood maltreatment than healthy individuals [81]. More recently, our group [33] compared the strength of the association between childhood maltreatment and self-reported psychotic symptoms in 447 healthy adult volunteers and 184 stable outpatients with schizophrenia or schizoaffective disorder and found very significant positive correlations between childhood maltreatment and self-reported symptoms in both groups. Notably, although patients scored significantly higher than controls on both history of childhood maltreatment and self-reported symptoms, the strength of the relationship (based 
on the resulting regression lines) did not differ between groups. Collectively, these data suggest that the experience of maltreatment during childhood may create a biological [82] or psychological [83] vulnerability for the development of psychotic symptoms along a continuum [84].

\section{Genetics}

Early work in large-scale family-based genetic studies [85-88] demonstrated an increased incidence of subclinical psychotic symptoms in the relatives of patients with schizophrenia, and unselected, population-based twin studies also showed substantial genetic contributions to subclinical symptoms [89-91]. Although somewhat limited, recent data seeking to elucidate the molecular genetic underpinnings of psychotic symptoms provide some preliminary support for the psychosis continuum.

\section{Genetic Association Studies}

The first direct study of the role of genetic variants in the expression of sub-syndromal psychotic symptoms was reported by Avramopoulos and colleagues [92]. They found that healthy young males who carried the val allele at the catechol-O-methyltransferase (COMT) Val158Met loci, which is associated with high enzymatic activity, reported higher scores on a measure of schizotypy than those carrying the met allele. Additional work examining variation in COMT has largely supported this initial finding [93-95]. More recently, several genetic variants originally identified as risk variants for schizophrenia have also been shown to relate to measures of subclinical psychotic symptoms. For example, variants in the calcium channel, voltage-dependent, $\mathrm{L}$ type, alpha $1 \mathrm{C}$ subunit gene $(C A C N$ $A 1 C)$ that have repeatedly been associated with schizophrenia [96] and bipolar disorder [97] have recently been associated with paranoid ideation in otherwise healthy participants [98]. Additionally, Stefanis and colleagues [99] found that common variants of the gene encoding zinc finger protein 804A (ZNF804A), also strongly associated with schizophrenia and bipolar disorder [100], were associated with paranoia and ideas of reference in otherwise healthy young males. Finally, Tomppo et al. [101] found that in a large population-based epidemiological sample, a variant in the disrupted in schizophrenia 1 $(D I S C 1)$ gene was significantly associated with the severity of negative symptoms. Collectively, these data suggest that genetic variation may, at least in some way, contribute to the expression of psychotic symptoms across the continuum.

\section{Neuroimaging}

There is a relatively small literature using neuroimaging to explore the neural basis of subclinical psychosis. The majority of papers have employed structural magnetic resonance imaging (sMRI) techniques to assess individual differences in gray matter (GM) volume and thickness. Decreased GM volume has been reported in the frontal and temporal lobes including the pars orbitalis and rostral middle frontal cortex [102•], the lateral and medial orbital frontal cortex [103], the inferior temporal gyrus [104], and the left and right putamen [105], with decreased cortical thickness observed in temporal regions [119]. However, there have also been reports of increased volume and thickness, with Jacobsen and colleagues [104], reporting larger GM volume in middle and superior temporal gyri, the angular gyrus, and orbitofrontal cortex in at-risk children, and Cordova-Palomera and colleagues [106] showing relationships between symptom scores and cortical thickness that varied based on season of birth, an environmental risk factor.

White matter in subclinical psychosis has been assessed using volumetric measures as well as diffusion tensor imaging (DTI). Decreases in fractional anisotropy (FA), a putative measure of white matter integrity, have been described in the inferior frontal occipital fasciculus [119, 121], as well as the cingulum bundle and inferior longitudinal fasciculus [119]. Moreover, the level of hallucinatory symptoms experienced by patients, their unaffected siblings, and healthy controls all showed a negative correlation with whole-brain FA [107]. However, in patients with schizophrenia, relatives, and individuals with schizotypal features, symptomatology also showed a specific positive relationship with the arcuate fasciculus $[107,108]$. The uncinate fasciculus, a fronto-temporal tract, has shown mixed results, with findings of either increased FA on the left [108] or increased asymmetry such that the right hemisphere had higher FA than the left [102•].

There have been relatively few functional investigations; these have demonstrated differences in functional magnetic resonance imaging (fMRI) activation during theory of mind [109], emotional processing [110], and social reflection [111] as well as differences in between network functional connectivity during resting-state fMRI [112•]. Finally, a positron emission tomography (PET) investigation revealed no difference in dopamine synthesis capacity in healthy individuals who experienced hallucinations [113].

In the existing neuroimaging work, there is substantial variability in age, as well as diagnostic approach. The most common clinical method for ascertainment of subclinical samples for imaging appears to be the CAPE $[103,105,106,109,110]$. However, other methods such as structured clinical interviews and scales focused on specific symptom domains have also been employed. In general, the field of neuroimaging in subclinical psychosis is in the early stages, and while there is 
evidence for decreases in GM, decreases in FA, and alterations in functional activation, the presence of conflicting findings, even within this small literature, highlights the clear need for further research in this area.

\section{Conclusions}

Collectively, the work reviewed here provides considerable support for a view of psychosis as a phenotype that can be examined across a continuum in general population samples. However, as recently reviewed by Kwapil and Vidal [12], the study of the symptoms comprising the psychosis continuum has been hindered by the lack of clearly defined constructs and the absence of a consensus model of how these symptoms relate to psychotic illness. Nevertheless, the emerging data holds considerable promise for advancing our understanding of both risk and resilience to psychiatric disorders characterized by psychosis that would not be possible through the study of patient samples alone.

\section{Compliance with Ethics Guidelines}

Conflict of Interest Pamela DeRosse and Katherine Karlsgodt have no relevant conflicts to disclose.

Human and Animal Rights and Informed Consent This article does not contain any studies with human or animal subjects performed by the author.

\section{References}

Papers of particular interest, published recently, have been highlighted as:

- Of importance

•- Of major importance

1. Beer MD. The dichotomies: psychosis/neurosis and functional/ organic: a historical perspective. Hist Psychiatry. 1996;7(26 Pt 2):231-55.

2. Strauss JS. Hallucinations and delusions as points on continua function. Arch Gen Psychiatry. 1969;21:581-6.

3. David AS. Why we need more debate on whether psychotic symptoms lie on a continuum with normality. Psychol Med. 2010;40(12):1935-42.

4. Lawrie SM, Hall J, McIntosh AM, Owens DG, Johnstone EC. The 'continuum of psychosis': scientifically unproven and clinically impractical. Br J Psychiatry. 2010;197(6):423-5.

5. Kaymaz N, van Os J. Extended psychosis phenotype - yes: single continuum - unlikely. Psychol Med. 2010;40(12):1963-6.

6. Craddock N, Owen MJ. The Kraepelinian dichotomy-going, going but still not gone. Br J Psychiatry. 2010;196(2):92-5.

7. van Os J, Rutten BP, Poulton R. Gene-environment interactions in schizophrenia: review of epidemiological findings and future directions. Schizophr Bull. 2008;34(6):1066-82.
8. Johns LC, Kompus K, Connell M, Humpston C, Lincoln TM, Longden E, et al. Auditory verbal hallucinations in persons with and without a need for care. Schizophr Bull. 2014;40 Suppl 4: S255-64. This is an excellent paper characterizing the similarities and differences of auditory verbal hallucinations in clinical and non-clinical samples.

9. Meehl PE. Schizotaxia, schizotypy, schizophrenia. Am Psychol. 1962;17(12):827.

10. Meehl PE. Schizotaxia revisited. Arch Gen Psychiatry. 1989;46(10): 935-44.

11. Purcell SM, Wray NR, Stone JL, Visscher PM, O’Donovan MC, Sullivan PF, et al. Common polygenic variation contributes to risk of schizophrenia and bipolar disorder. Nature. 2009;460(7256): $748-52$.

12. Kwapil TR, \& Barrantes-Vidal N. Schizotypy: looking back and moving forward. Schizophr Bull 2014:sbu186.

13. Claridge G. The schizophrenias as nervous types. Br J Psychiatry. 1972;121(560):1-17.

14. Claridge G. 'The schizophrenias as nervous types' revisited. Br J Psychiatry. 1987;151(6):735-43.

15. Raine A. The SPQ: a scale for the assessment of schizotypal personality based on DSM-III-R criteria. Schizophr Bull. 1991;17(4): 555.

16. Stefanis NC, Hanssen M, Smirnis NK, Avramopoulos DA, Evdokimidis IK, Stefanis CN, et al. Evidence that three dimensions of psychosis have a distribution in the general population. Psychol Med. 2002;32(02):347-58.

17. Nuevo R, Chatterji S, Verdes E, Naidoo N, Arango C, AyusoMateos JL. The continuum of psychotic symptoms in the general population: a cross-national study. Schizophr Bull. 2012;38(3): 475-85.

18.• Linscott RJ, van Os J. An updated and conservative systematic review and meta-analysis of epidemiological evidence on psychotic experiences in children and adults: on the pathway from proneness to persistence to dimensional expression across mental disorders. Psychol Med. 2013;43(6):1133-49. This is an excellent meta analysis examining a wide range of variables related to the psychosis continuum] found that nearly all of the demographic and experiential risk factors for psychotic disorders predicted greater risk of subclinical psychotic symptoms in otherwise healthy individuals.

19. Peralta V, Cuesta MJ. A dimensional and categorical architecture for the classification of psychotic disorders. World Psychiatry. 2007;6(2):100-1.

20. van Os J, Hanssen M, Bijl RV, Vollebergh W. Prevalence of psychotic disorder and community level of psychotic symptoms: an urban-rural comparison. Arch Gen Psychiatry. 2001;58:663-8.

21. Wigman JT, Vollebergh WA, Jacobs N, Wichers M, Derom C, Thiery E, et al. Replication of the five-dimensional structure of positive psychotic experiences in young adulthood. Psychiatry Res. 2012;197(3):353-5.

22. Laurens KR, Hobbs MJ, Sunderland M, Green MJ, Mould GL, Arango C, et al. Psychotic-like experiences in a community sample of 8000 children aged 9 to 11 years: an item response theory analysis. Psychol Med. 2012;42(7):1495-506.

23. Calkins ME, Moore TM, Merikangas KR, Burstein M, Satterthwaite TD, Bilker WB, et al. The psychosis spectrum in a young US community sample: findings from the Philadelphia Neurodevelopmental Cohort. World Psychiatry. 2014;13(3): 296-305.

24. Verdoux H, van Os J, Maurice-Tison S, Gay B, Salamon R, Bourgeois M. Is early adulthood a critical developmental stage for psychosis proneness? A survey of delusional ideation in normal subjects. Schizophr Res. 1998;29(3):247-54. 
25. Peters ER, Joseph SA, Garety PA. Measurement of delusional ideation in the normal population: introducing the PDI (Peters et al. Delusions Inventory). Schizophr Bull. 1999;25(3):553-76.

26. Cougnard A, Marcelis M, Myin-Germeys I, De Graaf R, Vollebergh W, Krabbendam L, et al. Does normal developmental expression of psychosis combine with environmental risk to cause persistence of psychosis? A psychosis proneness-persistence model. Psychol Med. 2007;37(4):513-28.

27. Chapman LJ, Chapman JP, Kwapil TR, Eckblad M, Zinser MC. Putatively psychosis-prone subjects 10 years later. J Abnorm Psychol. 1994;103(2):171-83.

28. Poulton R, Caspi A, Moffitt TE, Cannon M, Murray R, Harrington H. Children's self-reported psychotic symptoms and adult schizophreniform disorder: a 15-year longitudinal study. Arch Gen Psychiatry. 2000;57(11):1053-8.

29. Cannon M, Caspi A, Moffitt TE, Harrington H, Taylor A, Murray $\mathrm{RM}$, et al. Evidence for early-childhood, pan-developmental impairment specific to schizophreniform disorder: results from a longitudinal birth cohort. Arch Gen Psychiatry. 2002;59(5):449-56.

30. Hanssen M, Bak M, Bijl R, Vollebergh W, van Os J. The incidence and outcome of subclinical psychotic experiences in the general population. Br J Clin Psychol. 2005;44(Pt 2):181-91.

31. Welham J, Scott J, Williams G, Najman J, Bor W, O'Callaghan M, et al. Emotional and behavioural antecedents of young adults who screen positive for non-affective psychosis: a 21-year birth cohort study. Psychol Med. 2009;39(4):625.

32. Fisher, HL, Caspi, A, Poulton R, Meier MH, Houts R, Harrington H, \& Moffitt TE. Specificity of childhood psychotic symptoms for predicting schizophrenia by 38 years of age: a birth cohort study. Psychol Med 2013;1-10.

33. DeRosse P, Nitzburg GC, Kompancaril B, Malhotra AK. The relation between childhood maltreatment and psychosis in patients with schizophrenia and non-psychiatric controls. Schizophr Res. 2014;155(1):66-71.

34. Krabbendam L, Myin-Germeys I, De Graaf R, Vollebergh W, Nolen WA, Iedema J, et al. Dimensions of depression, mania and psychosis in the general population. Psychol Med. 2004;34(07):1177-86.

35. Yung AR, Buckby JA, Cotton SM, Cosgrave EM, Killackey EJ, Stanford C, et al. Psychotic-like experiences in nonpsychotic helpseekers: associations with distress, depression, and disability. Schizophr Bull. 2006;32(2):352-9.

36. Armando M, Nelson B, Yung AR, Ross M, Birchwood M, Girardi $\mathrm{P}$, et al. Psychotic-like experiences and correlation with distress and depressive symptoms in a community sample of adolescents and young adults. Schizophr Res. 2010;119(1):258-65.

37. Wigman JTW, Lin A, Vollebergh WAM, van Os J, Raaijmakers QAW, Nelson B, et al. Subclinical psychosis and depression: cooccurring phenomena that do not predict each other over time. Schizophr Res. 2011;130(1):277-81.

38. Klaassen RMC, Heins M, Luteijn LB, van der Gaag M, van Beveren NJM. Depressive symptoms are associated with (sub) clinical psychotic symptoms in patients with non-affective psychotic disorder, siblings and healthy controls. Psychol Med. 2013;43(04):747-56.

39. Boeker H, Kleiser M, Lehman D, Jaenke L, Bogerts B, Northoff G. Executive dysfunction, self, and ego pathology in schizophrenia: an exploratory study of neuropsychology and personality. Compr Psychiatry. 2006;47(1):7-19.

40. Chemerinski E, Triebwasser J, Roussos P, Siever LJ. Schizotypal personality disorder. J Personal Disord. 2012;27(5):1-28.

41. Margetic BA, Jakovljevic M, Brataljenovic T, Sumic M. Personality and schizophrenia: psychobiological model and its relationship with comorbidity. Psychiatr Danub. 2009;21(3): 356-60.
42. Claridge G, McCreery C, Mason O, Bentall R, Boyle G, Slade P, et al. The factor structure of 'schizotypal 'traits: a large replication study. Br J Clin Psychol. 1996;35(1):103-15.

43. Hori H, Matsuo J, Teraishi T, Sasayama D, Kawamoto Y, Kinoshita Y, et al. Schizotypy and genetic loading for schizophrenia impact upon neuropsychological status in bipolar II and unipolar major depressive disorders. J Affect Disord. 2012;142(1): 225-32.

44. Kwapil TR, Barrantes-Vidal N, Silvia PJ. The dimensional structure of the Wisconsin schizotypy scales: factor identification and construct validity. Schizophr Bull. 2008;34(3):444-57.

45. Barrantes-Vidal N, Lewandowski KE, Kwapil TR. Psychopathology, social adjustment and personality correlates of schizotypy clusters in a large nonclinical sample. Schizophr Res. 2010;122(1):219-25.

46. Rado S. Dynamics and classification of disordered behavior. Am J Psychiatry. 1953;110:406-16.

47. Chapman LJ, Chapman JP. Scales for rating psychotic and psychotic-like experiences as continua. Schizophr Bull. 1980;6(3):476

48. Eysenck HJ. The learning theory model of neurosis - a new approach. Behav Res Ther. 1976;14(4):251-67.

49. Cloninger CR, Przybeck TR, Svrakic DM, Wetzel RD. The temperament and character inventory (TCI): a guide to its development and use. St. Louis: Washington University, Center for Psychobiology of Personality; 1994.

50. Daneluzzo E, Stratta P, Rossi A. The contribution of temperament and character to schizotypy multidimensionality. Compr Psychiatry. 2005;46(1):50-5.

51. Gaweda L, Kokoszka A. A relationship between hallucination proneness and character and temperament: a mediating role of meta-cognitive beliefs in nonclinical sample. Psychiatry Res. 2013;208(2):183-5.

52. Nitzburg GC, Malhotra AK, DeRosse P. The relationship between temperament and character and subclinical psychotic-like experiences in healthy adults. Eur Psychiatry. 2014;29(6):352-7.

53. Barch DM, Ceaser A. Cognition in schizophrenia: core psychological and neural mechanisms. Trends Cogn Sci. 2012;16(1):2734.

54. Siever LJ, Davis KL. The pathophysiology of schizophrenia disorders: perspectives from the spectrum. Am J Psychiatry. 2004;161(3):398-413.

55. Snitz BE, MacDonald AW, Carter CS. Cognitive deficits in unaffected first-degree relatives of schizophrenia patients: a metaanalytic review of putative endophenotypes. Schizophr Bull. 2006;32(1):179-94.

56. Barnett JH, McDougall F, Xu MK, Croudace TJ, Richards M, Jones PB. Childhood cognitive function and adult psychopathology: associations with psychotic and non-psychotic symptoms in the general population. Br J Psychiatry. 2012;201(2):124-30.

57. Gooding DC, Braun JG. Visuoconstructive performance, implicit hemispatial inattention, and schizotypy. Schizophr Res. 2004;68(2):261-9.

58. Barrantes-Vidal N, Fananas L, Rosa A, Caparros B, Riba MD, Obiols JE. Neurocognitive, behavioural and neurodevelopmental correlates of schizotypy clusters in adolescents from the general population. Schizophr Res. 2003;61:293-302.

59. Tsakanikos E, Claridge G. Less words, more words: verbal fluency as a function of 'positive' and 'negative' schizotypy. Personal Individ Differ. 2005;39:705-13.

60. Cochrane M, Petch I, Pickering AD. Aspects of cognitive functioning in schizotypy and schizophrenia: evidence for a continuum model. Psychiatry Res. 2012;196(2):230-4.

61. Matheson S, Langdon R. Schizotypal traits impact upon executive working memory and aspects of IQ. Psychiatry Res. 2008;159(1): 207-14. 
62. Peters ER, Pickering AD, Hemsley DR. 'Cognitive inhibition' and positive symptomatology in schizotypy. Br J Clin Psychol. 1994;33(1):33-48.

63. Park S, Lenzenweger MF, Püschel J, Holzman PS. Attentional inhibition in schizophrenia and schizotypy: a spatial negative priming study. Cogn Neuropsychiatry. 1996;1(2):125-50.

64. Chen EY, Lam LC, Chen RY, Nguyen DG, Chan CK, Wilkins AJ. Neuropsychological correlates of sustained attention in schizophrenia. Schizophr Res. 1997;24(3):299-310.

65. Chen WJ, Liu SK, Chang CJ, Lien YJ, Chang YH, Hwu HG. Sustained attention deficit and schizotypal personality features in nonpsychotic relatives of schizophrenic patients. Am J Psychiatr. 1998;155(9):1214-20.

66. Poreh AM, Ross TP, Whitman RD. Reexamination of executive functions in psychosis-prone college students. Personal Individ Differ. 1995;18(4):535-9.

67. LaPorte DJ, Kirkpatrick B, Thaker GK. Psychosis-proneness and verbal memory in a college student population. Schizophr Res. 1994;12(3):237-45.

68. Suhr JA. Executive functioning deficits in hypothetically psychosis-prone college students. Schizophr Res. 1997;27(1): 29-35.

69. Lenzenweger MF, Gold JM. Auditory working memory and verbal recall memory in schizotypy. Schizophr Res. 2000;42(2):10110.

70. Dinn WM, Harris CL, Aycicegi A, Greene P, Andover MS. Positive and negative schizotypy in a student sample: neurocognitive and clinical correlates. Schizophr Res. 2002;56(1):171-85.

71. Spitznagel MB, Suhr JA. Executive function deficits associated with symptoms of schizotypy and obsessive-compulsive disorder. Psychiatry Res. 2002;110(2):151-63.

72. Suhr JA, Spitznagel MB. Factor versus cluster models of schizotypal traits. II: relation to neuropsychological impairment. Schizophr Res. 2001;52(3):241-50.

73. Kim MS, Oh SH, Hong MH, Choi DB. Neuropsychologic profile of college students with schizotypal traits. Compr Psychiatry. 2011;52(5):511-6.

74. Korponay C, Nitzburg GC, Malhotra AK, DeRosse P. Positive and negative subclinical symptoms and MCCB performance in nonpsychiatric controls. Schizophrenia research. Cognition. 2014;1(4):175-9.

75. Nuechterlein KH, Green MF, Kern RS, Baade LE, Barch DM, Cohen JD, et al. The MATRICS consensus cognitive battery, part 1: test selection, reliability, and validity. Am J Psychiatry. 2008;165(2):203-13.

76. Green MF. What are the functional consequences of neurocognitive deficits in schizophrenia? Am J Psychiatry. 1996;321-30

77. Green MF, Kern RS, Heaton RK. Longitudinal studies of cognition and functional outcome in schizophrenia: implications for MATRICS. Schizophr Res. 2004;72(1):41-51.

78. Keefe RS, Perkins DO, Gu H, Zipursky RB, Christensen BK, Lieberman JA. A longitudinal study of neurocognitive function in individuals at-risk for psychosis. Schizophr Res. 2006;88(1): 26-35.

79. Varese F, Smeets F, Drukker M, Lieverse R, Lataster T, Viechtbauer W, et al. Childhood adversities increase the risk of psychosis: a meta-analysis of patient-control, prospective-and cross-sectional cohort studies. Schizophr Bull. 2012;38:661-71.

80. Kelleher I, Keeley H, Corcoran P, Ramsay H, Wasserman C, Carli $\mathrm{V}, \&$ Cannon M. Childhood trauma and psychosis in a prospective cohort study: cause, effect, and directionality. Am J Psychiatry. 2013;170:734-41.

81. Kessler RC, McLaughlin KA, Green JG, Gruber MJ, Sampson NA, Zaslavsky AM, et al. Childhood adversities and adult psychopathology in the WHO World Mental Health Surveys. Br J Psychiatry. 2010;197(5):378-85.

82. Read J, Perry BD, Moskowitz A, Connolly J. The contribution of early traumatic events to schizophrenia in some patients: a traumagenic neurodevelopmental model. Psychiatry. 2001;64(4): 319-45.

83. Garety PA, Rigg A. Early psychosis in the inner city: a survey to inform service planning. Soc Psychiatry Psychiatr Epidemiol. 2001;36(11):537-44.

84. Janssen I, Krabbendam L, Bak M, Hanssen M, Vollebergh W, Graaf RD, et al. Childhood abuse as a risk factor for psychotic experiences. Acta Psychiatr Scand. 2004;109(1):38-45.

85. Schulsinger H. A ten year follow up of children of schizophrenic mothers clinical assessment. Acta Psychiatr Scand. 1976;53(5): 371-86.

86. Kety SS, Rosenthal D, Wender PH, Schulsinger F, \& Jacobsen B. The biologic and adoptive families of adopted individuals who became schizophrenic: prevalence of mental illness and other characteristics. Nat Schizophr. 1978;25-37.

87. Kendler KS, McGuire M, Gruenberg AM, O'Hare A, Spellman M, Walsh D. The Roscommon Family Study. IV. Affective illness, anxiety disorders, and alcoholism in relatives. Arch Gen Psychiatry. 1993;50(12):952-60.

88. Tienari P, Wynne LC, Läksy K, Moring J, Nieminen P, Sorri A, et al. Genetic boundaries of the schizophrenia spectrum: evidence from the Finnish Adoptive Family Study of Schizophrenia. Am J Psychiatr. 2003;160(9):1587-94.

89. Kendler KS, Hewitt J. The structure of self-report schizotypy in twins. J Personal Disord. 1992;6(1):1-17.

90. MacDonald III AW, Pogue-Geile MF, Debski TT, Manuck S. Genetic and environmental influences on schizotypy: a community-based twin study. Schizophr Bull. 2001;27(1):47.

91. Linney YM, Murray RM, Peters ER, MacDonald AM, Rijsdijk F, Sham C. A quantitative genetic analysis of schizotypal personality traits. Psychol Med. 2003;33(5).

92. Avramopoulos D, Stefanis NC, Hantoumi I, Smyrnis N, Evdokimidis I, Stefanis CN. Higher scores of self reported schizotypy in healthy young males carrying the COMT high activity allele. Mol Psychiatry. 2002;7(7):706-11.

93. Schürhoff F, Szöke A, Chevalier F, Roy I, Méary A, Bellivier F, et al. Schizotypal dimensions: an intermediate phenotype associated with the COMT high activity allele. Am J Med Genet B Neuropsychiatr Genet. 2007;144(1):64-8.

94. Stefanis NC, Henquet C, Avramopoulos D, Smyrnis N, Evdokimidis I, Myin-Germeys I, et al. COMT Val158Met moderation of stress-induced psychosis. Psychol Med. 2007;37(11): 1651-6.

95. Leung WW, McClure MM, Siever LJ, Barch DM, Harvey PD. Catechol-O-methyltransferase Val158Met genotype in healthy and personality disorder individuals: preliminary results from an examination of cognitive tests hypothetically differentially sensitive to dopamine functions. Neuropsychiatr Dis Treat. 2007;3(6): 925.

96. Ripke S, O'Dushlaine C, Chambert K, Moran JL, Kähler AK, Akterin S, et al. Genome-wide association analysis identifies 13 new risk loci for schizophrenia. Nat Genet. 2013;45(10):1150-9.

97. Psychiatric GWAS Consortium Bipolar Disorder Working Group. Large-scale genome-wide association analysis of bipolar disorder identifies a new susceptibility locus near ODZ4. Nat Genet. 2011;43(10):977-83.

98. Roussos P, Bitsios P, Giakoumaki SG, McClure MM, Hazlett EA, New AS, et al. CACNA1C as a risk factor for schizotypal personality disorder and schizotypy in healthy individuals. Psychiatry Res. 2013;206(1):122-3.

99. Stefanis NC, Hatzimanolis A, Smyrnis N, Avramopoulos D, Evdokimidis I, van Os J, et al. Schizophrenia candidate 
gene ERBB4: covert routes of vulnerability to psychosis detected at the population level. Schizophr Bull. 2013;39(2): 349-57.

100. O'Donovan MC, Craddock N, Norton N, Williams H, Peirce T, Moskvina V, et al. Identification of loci associated with schizophrenia by genome-wide association and follow-up. Nat Genet. 2008;40(9):1053-5.

101. Tomppo L, Hennah W, Miettunen J, Järvelin MR, Veijola J, Ripatti S, et al. Association of variants in DISC1 with psychosis-related traits in a large population cohort. Arch Gen Psychiatry. 2009;66(2):134-41.

102. DeRosse P, Nitzburg GC, Ikuta T, Peters BD, Malhotra AK, \& Szeszko PR. 'Evidence from structural and diffusion tensor imaging for frontotemporal deficits in psychometric schizotypy'. Schizophr Bull. 2014. This is one of the first papers to demonstrate similarities in brain structural and functional correlates across the psychosis continuum using a range of imaging methods.

103. Pelletier-Baldelli A, Dean DJ, Lunsford-Avery JR, Smith Watts AK, Orr JM, Gupta T, et al. Orbitofrontal cortex volume and intrinsic religiosity in non-clinical psychosis. Psychiatry Res. 2014;222(3):124-30.

104. Jacobson S, Kelleher I, Harley M, Murtagh A, Clarke M, Blanchard M, et al. Structural and functional brain correlates of subclinical psychotic symptoms in 11-13 year old schoolchildren. Neuroimage. 2010;49(2):1875-85.

105. Mittal VA, Orr JM, Turner JA, Pelletier AL, Dean DJ, LunsfordAvery J, et al. Striatal abnormalities and spontaneous dyskinesias in non-clinical psychosis. Schizophr Res. 2013;151(13):141-7.

106. Cordova-Palomera A, Alemany S, Falcon C, Bargallo N, Goldberg $\mathrm{X}, \mathrm{Crespo-Facorro} \mathrm{B}$, et al. Cortical thickness correlates of psychotic experiences: examining the effect of season of birth using a genetically informative design. J Psychiatr Res. 2014;56:144-9.

107. Knochel C, O’Dwyer L, Alves G, Reinke B, Magerkurth J, Rotarska-Jagiela A, et al. Association between white matter fiber integrity and subclinical psychotic symptoms in schizophrenia patients and unaffected relatives. Schizophr Res. 2012;140(1-3): 129-35.

108. Smallman RP, Barkus E, Azadbakht H, Embleton KV, Haroon HA, Lewis SW, et al. MRI diffusion tractography study in individuals with schizotypal features: a pilot study. Psychiatry Res. 2014;221(1):49-57.

109. van der Meer L, Groenewold NA, Pijnenborg M, Aleman A. Psychosis-proneness and neural correlates of self-inhibition in theory of mind. PLoS ONE. 2013;8(7):e67774.

110. Modinos G, Pettersson-Yeo W, Allen P, McGuire PK, Aleman A, Mechelli A. Multivariate pattern classification reveals differential brain activation during emotional processing in individuals with psychosis proneness. Neuroimage. 2012;59(3):3033-41.

111. Brent BK, Coombs G, Keshavan MS, Seidman LJ, Moran JM, Holt DJ. Subclinical delusional thinking predicts lateral temporal cortex responses during social reflection. Soc Cogn Affect Neurosci. 2014;9(3):273-82.

112. Orr JM, Turner JA, Mittal VA. Widespread brain dysconnectivity associated with psychotic-like experiences in the general population. Neuroimage Clin. 2014;4:343-51. This is one of the first papers to demonstrate that subclinical psychosis may, similar to psychotic disorders, represent dysconnectivity in the brain.

113. Howes OD, Shotbolt P, Bloomfield M, Daalman K, Demjaha A, Diederen KM, et al. Dopaminergic function in the psychosis spectrum: an [18 F]-DOPA imaging study in healthy individuals with auditory hallucinations. Schizophr Bull. 2013;39(4):807-14. 